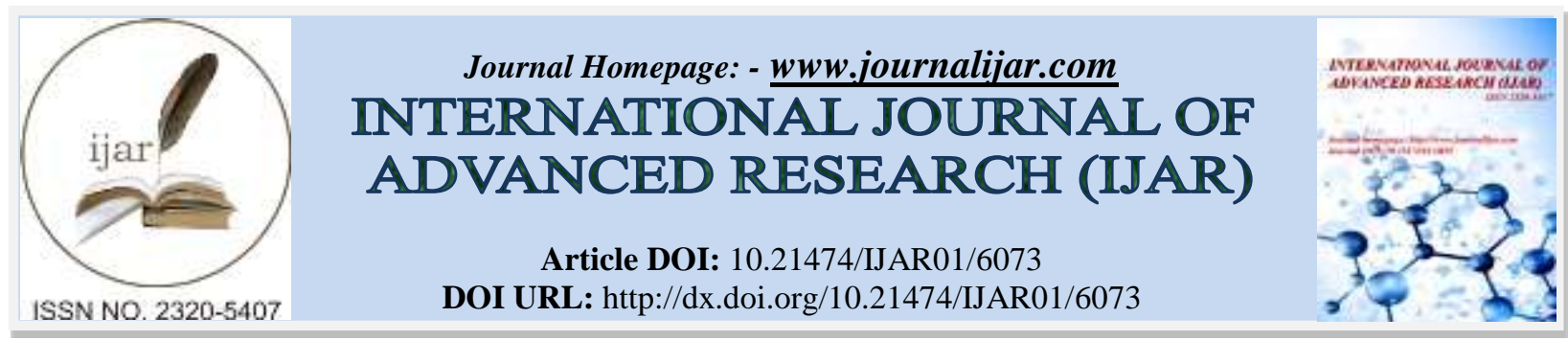

RESEARCH ARTICLE

\title{
PREVALENCE OF OBESITY IN RURAL SOUTH INDIA.
}

\section{Crps Krishna $^{1}$, Y. Srinivas ${ }^{2}$, Rama Krishna Reddy ${ }^{3}$, S. Srinivas ${ }^{4}$ and P. Srikanth ${ }^{5}$.}

1. Asso.Prof of Medicine, Kamineni Medical College, Narketpally, Telangana.

2. Asst.prof of medicine, Pinnamaneni Siddartha Medical College, Vijayawada, AP.

3. Asst.Prof of Medicine (FIMS Kadapa, AP).

4. Prof of Medicine (FIMS Kadapa, AP).

5. Asst. Prof of medicine (Pinnamanane Siddhardtha Medical College Vijyawada, AP).

\section{Manuscript Info}

(.........................

Manuscript History

Received: 15 October 2017

Final Accepted: 17 November 2017

Published: December 2017

\section{Abstract}

Obesity in (1) one of the most common Disorders in medical practice and most frustrating and difficult to treat.

Aim Of The Study: To Asser the prevalence of central and general obesity in a rural south India including Andhra Pradesh and Telangana States.

Methods: 769 Subject were included in this study. They were randomly selected to include in this population based cross selection survey conducted (in 2017) between March to May in the year 2017.

Result: Prevalence of overweight BMI $23-24.9 / \mathrm{kg} / \mathrm{m}^{2}$ and obesity in more in female $60 \%$ than male $40 \%$ baxdan age destitution in males. Obesity in max in 40-50 years age gap (50\%) and minimum in 20-30 age gap (8\%) in females. Max in $40-50$ years $(36 \%)$ minimum in $20-$ $25(9 \%)$ Baxdan BMI and of 769 subjects 518 were normal $(65 \%)$ Whereas $118(15 \%)$ were one of $129(18 \%)$ were pre Obese $19(25 \%)$ were obese 3(0.55) we morbid obese.

Copy Right, IJAR, 2017, All rights reserved.

\section{Introduction:-}

"Overweight" and "obesity" signify a range of greater weight than what should be normal for individual. It is calculated 0 height of the individual and determination of body mass index (BMI) and c provides information about health risk. It correlates with the amount of body fat.

Body fat can also be measured by other methods such as weight taken underwater or double energy x-ray absorptiometry. Beside BMI, waist circumference, lifestyle, such as high blood pressure or lake of exercise something predicts obesity-related diseases, such as high blood pressure, high cholesterol, and type 2 diabetes.

Observation:-

Table 1:- showing the various classes based on BMI

\begin{tabular}{|l|l|}
\hline Total Objects & 769 \\
\hline Over Weight & 115 \\
\hline Pre-Object & 139 \\
\hline Obese & 15 \\
\hline
\end{tabular}




\begin{tabular}{|l|l|}
\hline Morbid Obese & 03 \\
\hline Normal & 497 \\
\hline
\end{tabular}

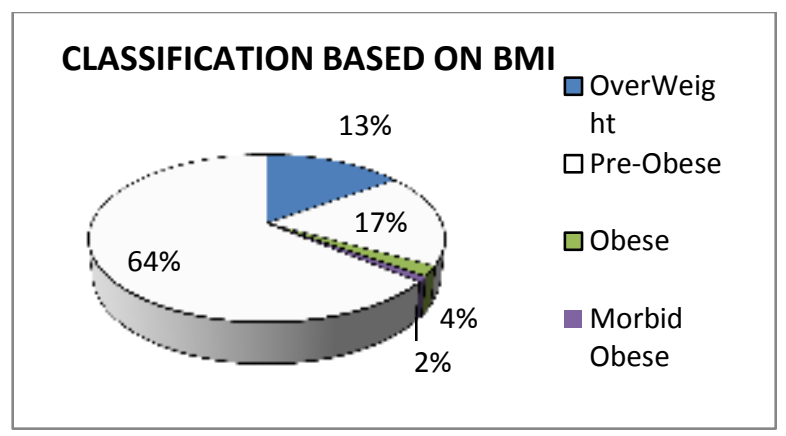

Table 2:- Showing the Age distribution of Obesity in MALE

Age in Years

20-30

30-35

$35-40$

$40-45$

45-50

$\begin{array}{lc}\text { Total } & \text { Percentage } \\ 113 & 14 \\ 49 & 6 \\ 103 & 13 \\ 428 & 53 \\ 118 & 14\end{array}$

\section{CLASSIFICATION BASED IN AGE MALE}

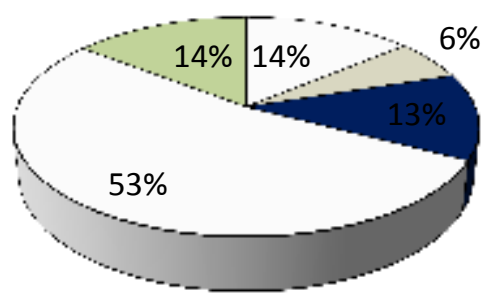

$\square$ 20-30

$\square$ 30-35

35-40

$\square 40-45$

$\square 45-50$

Table3:- Showing the Age distribution of Obesity in FEMALES

Age in Years Total

20-30

$30-35$

$35-40$

56

Percentage

$40-45$

81

10

105

15

45-50

203

20

38

$93 \quad 17$ 


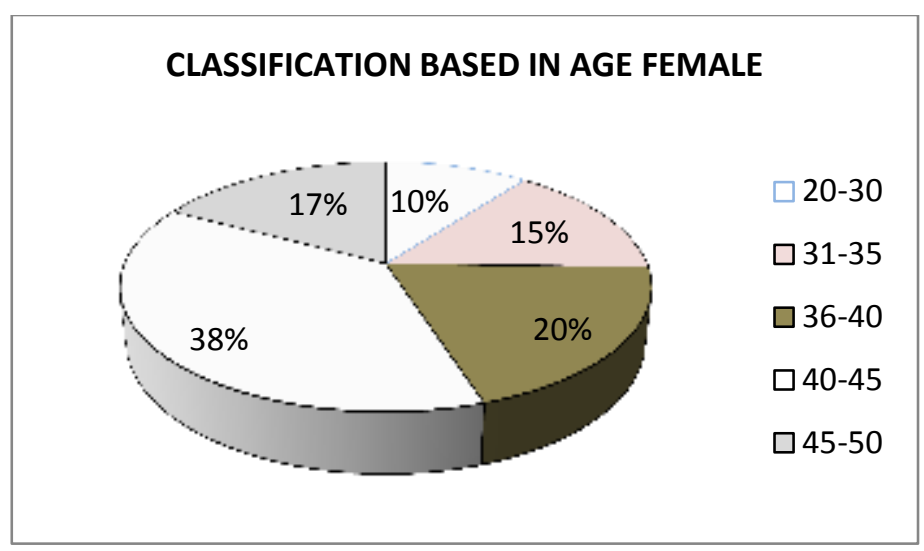

Age Incidence:-

Depending on age destitution in males the prevalence of obesity was maximum in the 40-45 yrs group (53\%) and minimum in 30-35 years Group (6\%). In Females maximum was 40-45 yrs (38\%), minimum was 20-30 years $(10 \%)$.

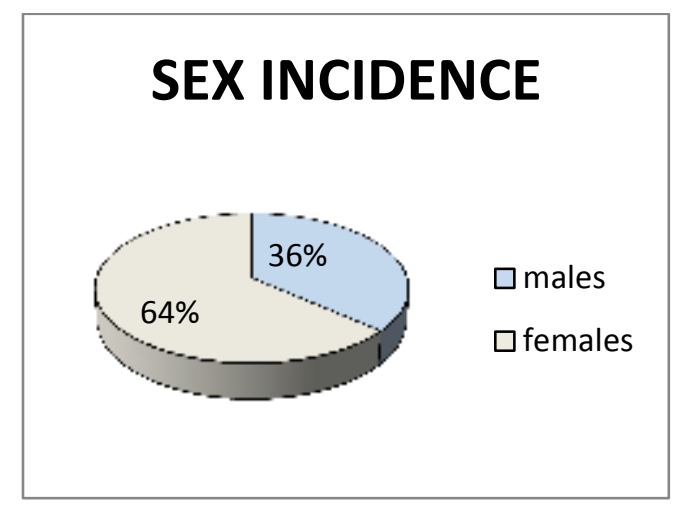

\section{Conclusion:-}

In normal prevalence of south India. The prevalence of central and general obesity in high among male and female with the use of weight proposed cut off points for Asian population.

\section{Discussion:-}

According to world health organization (WHO), Obesity as one of the most upcoming public health problems in developing counters. WHO Statics Report 2012 states that one in six adults is obese. WHO estimates approximately about 2.8 million individual deaths occur due to overweight or obesity. Obesity is now being considered as a disease which is usually associated with other co-morbidities like diabetes, hypertension, dyslipidemias and cardiovascular disease. Obesity can be classified as generalized obesity (Go) and abdominal obesity (AO). Individuals with obesity are exposed to greater mortality and morbidity compared to normal individuals. India having above 125 core people is one of the largest populated countries of world. Several studies from different parts of India showed an increased prevalence of obesity. But many of these reports have been from areas of urban India. These different studies of Obesity have followed several methods and definition until now; there has been no nationality, approved study till date on the prevalence of obesity in India.

The term "overweight" and "obesity" have specific important in healthcare. Obesity denotes a range of weight height. Determination of body mass index (BMI) can provide more information about health risks. For adults, overweight and obesity range are determined by using weight and height to calculate the body mass index (BMI). It correlates with the body fat.. Besides BMI, waist circumference, high blood pressure, high blood pressure, high cholesterol and type 2 diabetes or lack of exercise are also related to Obesity. 


\section{References:-}

1. Bason RB - telling pts. They are one weight or obese an insult efficitance intervention arches Int Red. 2011 feb 28; 171(4); 321 -2 (PM11) 21359808).

2. World Health Organization (WHO). Obesity: preventing and managing the global epidemic. Report of a WHO consultation (1-253). World Health Organ Teach RepSer.2000; 894:i-xii.[PubMed]

3. Geneva: WHO; 2012[accessed on November 28, 2012].World Health Organization (WHO).Health Statistics 2012.Available from:http:/ www.who.int/gho/publication/world_health_statistics/EN_WHS2012_Full.pdf.

4. James WPT, Jackson-Leach R, Ni Mhurchu C, Kalamara E, Shayeghi M, Rihby NJ,et al. Overweight and Obesity (high body mass index)In: Ezzati M, Lopez AD, Rodgers A, Murray CJL, editors. Comparative quantification of attributable to selected major risk factors. I. Geneva: World Health Organization; 2004.pp.497596.

5. Flegal KM, Kit BK,orpana H, Graubard BI, Association of all- cause mortality with overweight and Obesity using standard body mass index categories: a systematic review and meta-analysis. JAMA. 2013; 309:7182.[PMC free article ][PubMed]

6. Geneva: Switzerland, WHO; 2009. [Accessed on February 3, 2014]. World Health Organization (WHO).Global health risks: mortality and burden of disease attributable to selected major risks. Available from: http://www.who.int/healthinfo/global_burden_disease/Global Health risk_repo rt_full.pdf.

7. Mohan V, Deepa R. Obesity \& abdominal Obesity in Asian Indians. Indian J Med Res.2006;123:5936.[PubMed]

8. Bhardwaj S, Misra A, Misra R, Goel K, Bhatt SP, Rastogi KV, et al.High prevalence of abdominal, intraabdominal and subcutaneous adiposity and clustering of risk factors among urban Asian Indians in North India. PLoS One. 2011;6:e24362.[PMC free article] [PubMed]

9. Deep M, Farooq S, Deep R, Manjula D, Mohan V. prevalence and significance of generazed and central body obesity in an urban Asian Indian population in Chennai, India (CURES: 47) Eur J Clin Nutr.2009;63:25967.[PubMed]

10. Misra A, Khurana L. Obesity and the metabolic syndrome in developing countries. J Clin Endocrinol Metab . 2008; 93(11 suppl 11):s9-30.[Pubmed] 